INFORMÁTICA NA EDUGAĢ̃̃̃:

teoria \& prática Porto Alegre, v.9, n.1, jan./jun. 2006. ISSN 1516-084X

\title{
A Infância e a Modernidade do Ciberespaço: os Desafios da Interação entre Griança e Computador
}

Eloiza da Silva Gomes de Oliveira

Raquel Marques Villardi

\section{The Childhood and the Modernity of the Cyberspace: the Challenges of the Interaction Child - Computer}


INFORMÁTICA NA EDUGAĞ̃̃O:

teoria \& prática Porto Alegre, v.9, n.1, jan./jun. 2006. ISSN 1516-084X

Resumo: O texto discute criticamente aspectos da relação da criança com o computador, e os seus efeitos na Educação. Oposta à tendência tradicional da Pedagogia, a inclusão dos meios digitais na aprendizagem é uma realidade. Apresenta resultados de uma pesquisa com material pedagógico para a Literatura Infantojuvenil, comparando os efeitos da utilização de material tradicional, de material informatizado e da conjugação dos dois tipos de recurso. Destaca os efeitos da interação criança - computador e da importância da cultura digitalizada, no desenvolvimento cognitivo da criança. Para melhor compreender as etapas através das quais essa interação ocorre, utilizamos uma adaptação do estudo desenvolvido por Abigail Housen sobre a seqüência do desenvolvimento do modo das pessoas verem obras de arte. Propomos cinco estágios explicativos da evolução da relação anteriormente mencionada: Descritivo, enumerativo ou narrativo, construtivo, classificativo, interpretativo e recriativo.

Palavras-chave: Interação criança-computador. Desenvolvimento humano. Aprendizagem. Tecnologia de informação e comunicação.

Abstract: The text discusses aspects of the child's relationship with the computer and their effects in the Education. Opposed to the traditional tendency of Pedagogy, the inclusion of digital means in the learning is a reality. We present results of a research with pedagogic material for the Literature for children and young people, comparing the effects of the use of traditional didactic material, the use of computerized material and the conjugation of the two types. We detached the effects of child's - computer interaction and the importance of the digital culture in the child's cognitive development. For understand the stages of the development of this interaction, we used an adaptation of the study developed by Abigail Housen about the sequence of the development in the people's manners to see the art. We propose five explanatory apprenticeships of the evolution of the previously mentioned relationship: descriptive, narrative, constructive, classification, interpretative and creation.

Keywords: Child-computer interaction. Human development. Learning. Information and communication technology.

OLIVEIRA, Eloiza da Silva Gomes de; VILLARDI, Raquel Marques. A infância e a modernidade do ciberespaço: os desafios da interação entre criança e computador. Informática na Educação: teoria \& prática, Porto Alegre, v.8, n.2, p.53-64, jul./dez. 2006. 


\section{Introdução}

É de conhecimento geral a importância do processo de consolidação da identidade do ser humano. É ela que dá ao homem o sentido de individualidade, conjugado à integridade do Ego, que lhe permite estabelecer vínculos fortes e saudáveis com o outro e com os grupos.

Todas as teorias do desenvolvimento humano que conhecemos, apontam para um processo evolutivo da identidade de menos para mais amadurecida, de um menor para um maior grau de estruturação e de solidez.

A capacidade para as aprendizagens colaborativas e grupais e a intensa relação com os meios virtuais, no entanto, começa bem antes, em um momento que muitos chamam de pré-adolescência ou de idade escolar, ou ainda de média meninice, em que muitos dos processos cognitivos citados anteriormente são prenunciados.

O presente texto volta-se para um momento evolutivo entre seis e onze anos, em que as modernas tecnologias de informação e comunicação despertam a atenção e quase uma "fixação" por parte das crianças. Elas apresentam intensa motivação para o conhecimento e o manuseio de computadores, jogos e agendas eletrônicos, e outros artefatos do gênero.

Hipotetizamos que esta modalidade de relação transcende o plano objetivo, quando a criança descortina a multiplicidade de possibilidades de descoberta do mundo e de construção de conceitos, propiciada pelo "mergulho" nas modernas tecnologias de informação e comunicação e nos ambientes educativos virtuais. Trata-se de uma relação que toca o simbólico, o imaginário, envolvendo componentes emocionais e afetos. Não é um lápis, um caderno ou uma borracha, mas algo que tem cores, sons e movimentos, que "pulsa" e responde á criança, como se estivesse vivo.

Acreditamos, ainda, que esta possível transferência de afetos e de conteúdos inconscientes não substitui ou esvazia de sentido, mas completa a relação com o adulto educador e interfere na evolução da identidade da criança.

Discutir a relação da criança com o computador é indispensável nos dias de hoje. Presente no cotidiano de todos, parece que não podemos mais viver sem ele.

As crianças, em relação aos adultos que entraram em contato com o computador tardiamente, apresentam uma facilidade e uma desenvoltura surpreendentes. Livres da necessidade que nós, adultos, temos de "desaprender" coisas estabelecidas há muito tempo, as crianças mergulham, deslumbradas e curiosas, no ciberespaço, no mundo da informática e da virtualidade.

Algumas preocupações, no entanto, começam a surgir no horizonte dessa modernidade acelerada. Pierre Lévy tem sido um dos autores que alerta para certos aspectos críticos dessa nova forma de interação.

A quantidade e a qualidade de informação circulante colocam em risco profissões e instituições que até então intermediavam o acesso ao conhecimento. Fragilizados pela desintermediação e crescimento de transparência, os sujeitos só podem sobreviver e prosperar no 'ciberspace' efetuando sua migração de competências para a organização da inteligência coletiva. (Lévy, 1996, p.17).

No que diz respeito à Educação, nossa principal área de interesse, podemos dizer que se trata de uma relação "tensa". A Pedagogia mantém uma tendência que podemos cha- 


\section{INFORMÁTICA NA EDUCAÇ̃̃O:}

teoria \& prática Porto Alegre, v.9, n.1, jan.jun. 2006. ISSN 1516-084X

mar de "instrucionista" - ênfase em conteúdos neutros e aprendizagem mecânica; didáticas "instrumentais", meros aglomerados de conhecimentos teóricos e técnicos sobre o "fazer" pedagógico; avaliações voltadas para conhecimentos factuais, acenadas em propostas obsoletas de provas - uma perspectiva que só muito raramente ultrapassa a simples disseminação de informação.

Isso se constitui em um fator que complica a verdadeira inserção dos meios digitais na aprendizagem. Como combinar este paradigma tradicional do processo ensino-aprendizagem, com os desafios trazidos por esses novos recursos? Como enfrentar a tarefa do conhecimento moderno, objetalizado e passível de freqüentes desconstruções?

Como incluir na escola as múltiplas formas de comunicação e interação que nos são oferecidas pela tecnologia? E mais: até que ponto essa inclusão favorece ou não o desenvolvimento cognitivo da criança, permitindoIhe aprender mais e melhor?

Buscamos verificar, na pesquisa realizada, de que modo uma ação pedagógica efetiva seria capaz de alterar, substantivamente, a capacidade de ler da criança, ampliando, pela via da linguagem, as possibilidades de compreensão do mundo.

Nossas pesquisas anteriores na área da leitura indicavam que uma ação pedagógica assentada em bases sócio-interacionistas, mediada pelo lúdico, que tenha como meta aspectos específicos do desenvolvimento da criança, é capaz de gerar resultados bastante mais eficazes que os obtidos através da mera transmissão de informações.

Considerando o material didático elemento fundamental na concretização de uma concepção educativa e, em conseqüência, fator que favorece o processo de desenvolvimento infantil, criamos e desenvolvemos material didático-pedagógico para o trabalho com a Literatura Infanto-Juvenil, que investia maciçamente na habilidade da compreensão, modelando-o em veículo tradicional (papel) e em veículo informatizado (softwares), sempre a partir dos mesmos princípios norteadores e de uma única perspectiva metodológica (Villardi, 1997).

Trabalhamos com um universo de 1.413 crianças, divididas em três grupos: um utilizou só o material tradicional; outro, só o material informatizado; e, finalmente, o terceiro grupo utilizou ambas as mídias.

Partindo da leitura de determinados livros da literatura infantil, mapeamos o nível de compreensão obtido antes (avaliação inicial) e depois (avaliação final) do uso do material didático, em cada um dos grupos.

Desta forma, buscávamos verificar se os níveis de compreensão do texto escrito se alteravam:

1- após a utilização do material; e

2- de acordo com o tipo de mídia em que o material estava modelado.

Paralelamente, entrevistamos uma amostra dessas crianças, além de todos os professores responsáveis pelas turmas em que se realizou a pesquisa, com o intuito de saber a que mídia as crianças associavam maior prazer com o trabalho.

Os resultados obtidos, no que toca aos níveis de compreensão, estão expressos no Gráfico 1.

Por esses resultados percebe-se que 
INFORMÉTICA NA EDUCAÇ̃̃̃:

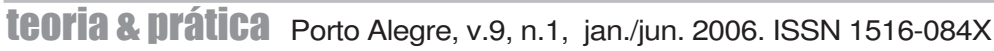

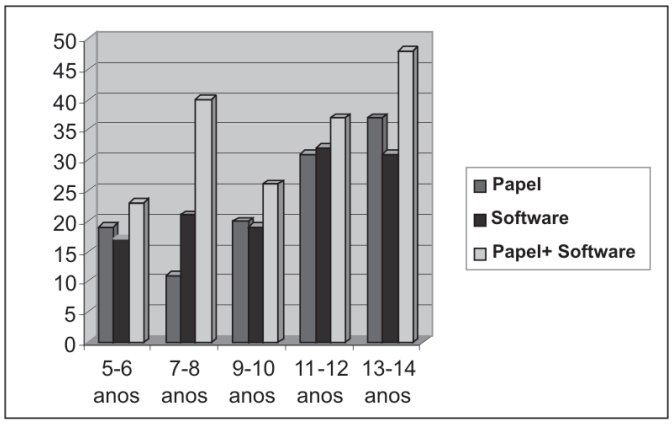

Gráfico 1 - Aumento percentual dos níveis de compreensão entre a avaliação inicial e a final, por faixa etária.

todos os grupos apresentaram melhoria na compreensão (entre 15 e 47\%), sendo maiores para as faixas etárias mais elevadas e para o grupo que trabalhou com ambas as mídias. Vale notar, ainda, que não há diferença substantiva entre os grupos que utilizaram material tradicional ou informatizado

No que diz respeito ao gosto pelo trabaIho, no entanto, é evidente a preferência pela mídia eletrônica, como demonstra o Gráfico 2, embora o envolvimento ocorra também com mídia impressa, o que atribuímos ao caráter lúdico do material utilizado.

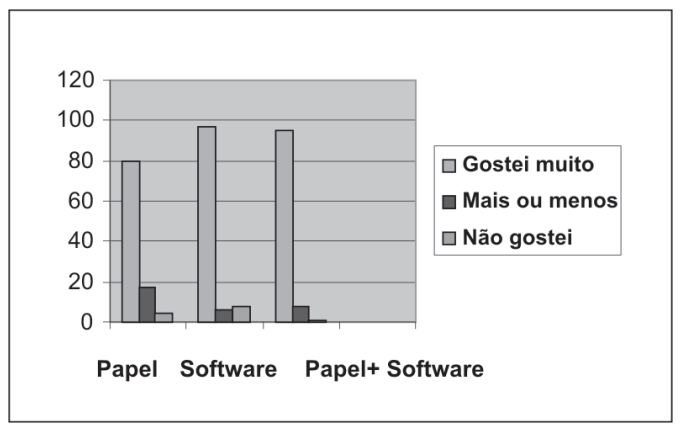

Gráfico 2 - Níveis percentuais de gosto pelo trabalho.

Tais resultados, se lidos à luz de uma elaboração teórica, como apresentamos a se- guir, sedimentam o caminho da tecnologia no interior da escola, não como panacéia salvacionista, mas como uma necessidade frente aos desafios de formação integral do cidadão deste início de milênio.

\section{A criança no período das operações concretas}

A ótica construtivista do estudo da aprendizagem, aqui representada pela epistemologia genética de Piaget e pelo sóciointeracionismo de Vygotsky, nos permite fugir às visões empirista e apriorística da produção do conhecimento pelo homem. Descreve, além do mais, um quadro de possibilidades em que a relação com o computador já pode ser introduzida e vivenciada não só de forma proveitosa, mas prazerosamente pela criança.

De acordo com essa visão, o conhecimento não está nem no sujeito nem no objeto, mas na interação entre ambos. Agindo sobre os objetos do mundo e sofrendo a ação destes, o homem vai ampliando a sua capacidade de conhecer e, conseqüentemente, o próprio conhecimento.

É preciso que não se entenda a interação como um mero processo de troca, um "toma lá - dá cá", mas como um processo dialético, de interferência e produção de mudanças mútuas. Na medida em que confere novos significados ao objeto conhecido, o homem transforma-se e transforma-o, de tal forma que podemos dizer que ambos nunca mais serão os mesmos.

Para objetivar este estudo, vamos especificar um estágio de desenvolvimento, como já foi dito, embora consideremos que o próprio Piaget valorizava a sucessão de aquisições, e não as idades ou estágios em que elas ocorriam. 


\section{INFORMÁTICA NA EDUGACÃO:}

... para que haja estágios, é necessário primeiramente que a ordem de sucessão das aquisições seja constante. Não a cronologia, mas a ordem de sucessão. Podemos caracterizar os estágios numa população dada por uma cronologia, mas essa cronologia é extremamente variável; ela depende da experiência anterior dos indivíduos e não somente de sua maturação, e depende principalmente do meio social que pode alterar ou retardar o aparecimento de um estágio, ou impedir sua manifestação. (Piaget, 1978, p. 235).

A criança de seis a dez anos, no entendimento de Piaget, encontra-se em um momento especial de seu desenvolvimento cognitivo. Superando progressivamente o egocentrismo do pensamento, admite relações de cooperação, brincando e aprendendo com o outro; as assimilações e acomodações ocorrem de forma mais ágil, ampliando notavelmente os esquemas mentais; a formação de classes e séries já ocorre mentalmente, com a internalização de ações físicas como operações - ações mentais; apresenta facilidade de operar concretamente, mas a dificuldade em solucionar problemas verbais faz com que opere frequentemente com tentativas e erros.

Aos poucos, o raciocínio lógico vai-se impondo sobre a intuição e a percepção, a criança organiza as informações em sistemas, relacionando-as no interior dos mesmos.

Se pudermos listar algumas das importantes aquisições desta fase, optaremos pela reversibilidade do pensamento, a conservação de quantidades, a relação ordinal, a classificação operatória e a inclusão hierárquica.

À abstração empírica, retirada diretamente dos objetos ou da ação exercida sobre eles, vai somar-se a abstração reflexionante, obtendo o conhecimento da coordenação das ações - e mais tarde da antecipação das possíveis ações - exercidas sobre o objeto. Ela conduz, progressivamente, à abstração refletida, em que se dá a consciência do processo que levou o homem a construir o conhecimento.

Juntamente com esses avanços cognitivos a criança, nesta fase de desenvolvimento, apresenta notável crescimento das possibilidades de utilização da faculdade da linguagem, atingindo a fala socializada e adquirindo uma capacidade crescente de utilizar a linguagem em variados sistemas simbólicos. Tudo contribui para isto, inclusive a esquematização e progressiva coordenação do corpo, dos esquemas mentais e do universo conceitual já construído.

Isto implica também um alargamento do campo representacional, com a produção de novos e variados sentidos através da linguagem, já que, como observa Luke (1996), a construção do sujeito é social e a prática social tem caráter discursivo.

O impacto do desenvolvimento da linguagem, nessa fase, é indiscutível. O inicio da escolarização formal coincide com o que Piaget chama de "inteligência verbal ou refletida". Ela se estende pelos anos iniciais do Ensino Fundamental, quando as crianças agem sobre os objetos para interiorizarem progressivamente os conceitos, abstraídos das ações, e constroem as operações mentais.

A irreversibilidade inicial do raciocínio persiste, porque a compreensão das relações lógicas da linguagem necessita da construção anterior, através das ações e suas coordenações gerais.

\section{Diz Piaget:}

(...) a aprendizagem de uma operação no plano verbal reproduzirá as peripécias às quais tinha dado lugar esta mesma aprendizagem no plano da ação: haverá uma defasagem entre as duas aprendizagens. (...) 
Ora, estas dificuldades são, ainda, muito nítidas no plano verbal entre sete e onze anos, ao passo que, no plano da ação, não existem mais... (Piaget, s. d., p. 199-200).

Por fim, é necessário destacar que a nossa criança também já alcançou grandes avanços em termos emocionais e sociais, atingindo maior autonomia em relação ao adulto e capacidade de tomar iniciativas e acentuado gosto por jogos e brincadeiras. Todo este crescimento, somado à ampliação da capacidade de interagir com o meio - de que falaremos agora - torna a criança apta a relacionar-se com ambientes virtuais de aprendizagem, em especial com o computador.

\section{A criança e o computador: novas formas de interação}

Comecemos por destacar a importância da interação social para o desenvolvimento e a aprendizagem da criança. $O$ conceito de interação social é um dos focos da obra de Vygotsky, que enfatiza a dialética entre o indivíduo e a sociedade, o intenso efeito da interação social, da linguagem e da cultura sobre a aprendizagem. Este processo é fundamental para a interiorização do conhecimento - ou transformação dos conceitos espontâneos em científicos - que ocorre quando se torna intrapsíquico o que antes era inter-psíquico. Vygotsky empresta valor especial à interação, quando enuncia quase todos os seus conceitos. Frawley, ao apresentar a concepção do teórico sobre a aquisição de pensamento superior pela criança, afirma:

A criança nasce em um mundo préestruturado. A influência do grupo sobre a criança começa muito antes do nascimento, tanto nas circunstâncias implícitas, históricas e socioculturais herdadas pelos indivíduos como nos preparos explícitos, físicos e sociais mais óbvios que os grupos fazem antecipando o indivíduo. Tudo isso exerce sua força até mesmo em tarefas cotidianas simples que requerem o gerenciamento e o emprego da ação individual. (Frawley, 2000, p. 91).

As aprendizagens realizadas com o auxílio do computador, e em ambientes colaborativos de aprendizagem (como é passível de acontecer, por exemplo, na Educação a Distância e em softwares em que a ação do usuário determina o andamento da estrutura do aplicativo) reforçam a idéia de que o conhecimento se constrói de forma compartilhada e de que isto tem forte efeito motivador para as crianças.

É possível perceber que a aprendizagem no Ciberespaço propicia, de forma progressiva, todas as formas de interação (desde a síncrona, quando o grupo interage ao mesmo tempo, mesmo que de lugares diferentes, como nas salas de aula virtuais; até a assíncrona, em que a interação ocorre em diferentes tempos e lugares - como nos fóruns e nas listas de discussão), permitindo sempre o encontro educacional pleno.

Martin \& Ahijado destacam a importância da comunicação propiciada pelos ambientes interativos:

Sem descartar nenhum dos materiais e meios, pois todos eles têm importantes funções a cumprir, realçando-se a importância de dispor de tecnologias que permitam uma comunicação sincrônica e o estabelecimento de um diálogo educativo entre os distintos atores do processo ensino - aprendizagem. (1999, p.25).

Outra virtude da ênfase no conceito de interação foi a derrubada do "mito" da interiorização na Psicologia, herança legada pelo subjetivismo a esta ciência. Os estudos sobre o "ser psicológico" migraram progressivamente para abordagens do "ser social". Este fato soma-se ao que foi dito sobre o conceito historicista de identidade. 


\section{INFORMÁTICA NA EDUGACQ̃̃O:}

teoria \& prática Porto Alegre, v.9, n.1, jan./jun. 2006. ISSN 1516-084X

Atividades inicialmente consideradas como componentes do mundo interior do homem passam, desse modo, a ter caráter social e cultural, lembrando o que Vygotsky (1989) afirmava sobre os processos intrapsíquicos serem antes, obrigatoriamente, inter-psíquicos, adquiridos através da interação social.

Como conseqüência podemos dizer que os construcionismos sociais destacam o papel determinante do lingüístico, do discursivo, e do significado na construção do nosso mundo mental.

É necessário constatar que, na atualidade, essas interações passam a ocorrer em planos que transcendem o real, demandando novas formas explicativas, modelos compreensivos e formas de mediação.

O próprio Vygotsky fala da utilização de elementos mediadores entre o sujeito e o objeto do conhecimento com que interage:

...o uso de meios artificiais - a transição para a atividade mediada - muda, fundamentalmente, todas as operações psicológicas, assim como o uso de instrumentos amplia de forma ilimitada a gama de atividades em cujo interior as novas funções psicológicas podem operar... (Vygotsky, 1989, p. 73)

Belloni (2001) fala de uma "cultura digitalizada", em que as crianças e os jovens de hoje estão imersos desde os primórdios da vida. A autora destaca, como características dessa cultura, a fragmentação e a extensão horizontal do conhecimento, além da possibilidade de transitar agilmente de um assunto para outro. Ela utiliza a metáfora do rizoma, para ilustrar a capilarização dessa aquisição de conhecimento.

Para Lévy esses elementos tecnológicos são "tecnologias da inteligência", que:

... reorganizam, de uma forma ou de outra, a visão de mundo de seus usuários e modificam seus reflexos mentais. (...) Na medida em que a informatização avança, certas funções são eliminadas, novas habilidades aparecem, a ecologia cognitiva se transforma...(Lévy, 1993, p. 54)

Pensando neste assunto nos ocorre citar as palavras de Santos, ao falar da acelerada mudança paradigmática que acompanha o conhecimento hoje.

\begin{abstract}
Vivemos um tempo atônito que ao debruçarse sobre si próprio descobre que os seus pés são um cruzamento de sombras, sombras que vêm do passado que ora pensamos já não sermos, ora pensamos não termos deixado ainda de ser; sombras que vêm do futuro que ora pensamos já sermos, ora pensamos nunca virmos a ser. (1996, p. 5)
\end{abstract}

Não há como desconhecer que essas "sombras" de que fala o autor, e que se referem à incerteza, ao deslumbramento e à perplexidade que acompanham o ser humano diante destas inovações que se sucedem de modo alucinante, estão presentes na criança ao relacionar-se com os ambientes educativos e, em especial, com o computador, atualíssimo objeto-fetiche que o simboliza.

O computador está presente na vida da criança da modernidade e afeta ativamente a construção da sua identidade. Ele é incorporado, juntamente com o "ethos tecnológico" da cultura, com variadas significações.

Primeiramente incorporado objetalmente como jogo, diversão, lazer, o computador precisa ser ressignificado para a representação como recurso de aprendizagem e, posteriormente, como instrumento de trabalho. Ele é responsável por importantes mediações e incorporado à identidade da criança "incluída digitalmente", utilizando uma expressão atual.

Dependendo do contexto social, pode ganhar várias representações no imaginário 
dos grupos: de símbolo de status a mera máquina de escrever dotada de mais recursos, de valioso recurso pedagógico a videogame sofisticado.

Em todas as circunstâncias, no entanto, acreditamos que as interações promovidas quando a "máquina" é utilizada como recurso na Educação, promovem forte mediação entre o homem e o conhecimento, afetando intensamente a identidade de quem aprende.

Similarmente ao que faz o adulto, interfere no que Vygotsky chama de "zona de desenvolvimento proximal";

\begin{abstract}
A zona de desenvolvimento proximal define aquelas funções que ainda não amadureceram, mas que estão em processo de maturação, funções que amadurecerão, mas que estão presentemente em estado embrionário. Essas funções poderiam ser chamadas de "brotos" ou "flores" do desenvolvimento, ao invés de "frutos" do desenvolvimento. O nível de desenvolvimento real caracteriza o desenvolvimento mental retrospectivamente, enquanto a zona de desenvolvimento proximal caracteriza o desenvolvimento mental prospectivamente. (Vygotsky, 1989, p.97).
\end{abstract}

É necessário, no entanto, que a relação entre a criança e o computador seja crítica e flexível, evitando o estabelecimento de uma "dependência digital". É necessário garantir o terceiro e mais elevado nível de interação, dos três que Sherman descreveu, ao estudar a interação com a web-page.

Considerando a interação como o grau em que o usuário é "afetado" pelas mensagens apresentadas, ela pode ser:

- Instrucionista (ou "navegacional") nível mais baixo de interação, rigidamente estruturado (interação com os links e os recursos da máquina, por exemplo).
- Funcional - nível médio de interação, estabelecido com os recursos para a pesquisa na Internet e o simples registro dos dados obtidos.

- Construcionista (ou adaptativa) - nível mais alto de interação, em que o usuário adapta os recursos às suas próprias necessidades e "processa" os resultados das "buscas", relacionando-os entre si e aplicando-os ao contexto que deseja.

O fulcro da questão parece-nos ser "recortar" na tão falada sociedade do conhecimento, através das múltiplas formas de interação, uma "sociedade da aprendizagem". Nela o homem precisa alcançar a plena cidadania no que se refere ao ato de aprender. Desta forma, ele poderá reconhecer-se e agir como aprendiz permanente, ao longo do ciclo vital, adquirindo ferramentas cognitivas para construir novos conhecimentos. Isto só ocorrerá através da constância e do aprimoramento da interação com as tecnologias de informação e comunicação, em constante mudança na sociedade.

\section{O estudo realizado e algumas conclusões}

A interação com o computador facilita, através da ativação de funções da zona de desenvolvimento proximal, o alcance de níveis mais elevados de desenvolvimento real. Nunca substitui o adulto / educador ou o grupo, mas multiplica as situações em que a mencionada zona é ativada.

Na pesquisa na área da leitura, citada anteriormente, (Villardi, 1997), observamos detidamente a amostra das crianças entrevistadas. Verificamos e registramos detalhadamente como cada uma interagia com o computador e depois, em um procedimento metodo- 


\section{INFORMÁTICA NA EDUCACÃ̃:}

teoria \& prática Porto Alegre, v.9, n.1, jan./jun. 2006. ISSN 1516-084X

lógico transversal, separamos as observações em três grupos: crianças até seis anos, crianças de seis a onze anos e crianças com mais de onze anos.

Tentamos atender, desta forma, três estágios de desenvolvimento descritos por Piaget: o período pré-operacional, o operatório concreto e o operacional formal, com ênfase no segundo.

Realizamos depois uma análise de similitude de características internamente em cada grupo e entre os grupos, verificando a existência de uma tendência comum, definidora de cada grupo e da forma como as crianças se relacionavam com o computador.

Precisávamos, no entanto, de um referencial teórico que nos ajudasse a caracterizar cada grupo, sem a pretensão de estabelecer tipologias, pois conhecemos as críticas que elas sofrem e a inconsistência das classificações delas decorrentes.

O nosso objetivo último é estabelecer, em fase posterior do estudo, procedimentos metodológicos que orientem o professor para facilitar e a otimizar a relação criança-computador.

Para melhor compreender as etapas através das quais essa interação ocorre, tomamos por empréstimo as que são enunciadas pela psicóloga cognitiva Abigail Housen, ao estudar a seqüência do desenvolvimento do modo das pessoas verem obras de arte.

Em 1983, ela publicou sua tese de doutorado, que apresentava uma teoria de estágios do desenvolvimento estético - "Five primary stages of aesthetic development" fundamentada em Arheinm, Bruner e Vygotsky. Criou, com Philip Yenawine, o mé- todo de arte educação "Estratégias de Pensamento Visual (EPV)".

Housen estudou aprofundadamente o olhar do observador da obra de arte, unindo em seu método teoria e prática e buscando a aprendizagem ativa e significativa. Sintetizou e categorizou as verbalizações dos sujeitos estudados em cinco estágios, ou seja, em cinco maneiras diferentes de dar sentido a uma obra de arte.

No primeiro os principiantes - narradores de histórias - centram o seu juízo de preferência no que gostam e conhecem; no segundo, os construtivistas criam quadros de referência, de acordo com valores do seu mundo; os observadores, na terceira fase descrita por Housen, classificam e enumeram o estilo, o tempo e a escola da obra de arte; no quarto estágio os interpretativos apelam ao significado das linhas, das cores e matizes; finalmente os recriativos, representantes do último estágio, que já observaram muitas obras de arte, possuem verdadeiramente capacidades de análise. A obra de arte para eles é como um velho amigo, mas continua a ter muitas coisas para revelar (Housen, 2000).

Adaptamos os cinco estágios, descritos acima, criando categorias interpretativas das características dos grupos de crianças observados na pesquisa. Temos, então, cinco estágios do desenvolvimento da interação entre a criança e o computador:

a) Descritivo, enumerativo, narrativo - Existe uma curiosidade acentuada e uma exploração intensa do computador. A criança quer conhecer tudo, pergunta como funciona, quer experimentar todas as possibilidades, sempre acentuando a feição lúdica do contato. 
b) Construtivo - Aqui o computador passa a ter uma existência própria, é incorporado à realidade e deixa de ser apenas um brinquedo, adquirindo nuances utilitárias e funcionais.

c) Classificativo - Surge o interesse pela história do computador - como surgiu, que modelos, marcas e programas existem, quais são e os mais modernos e de maior e menor preço.

d) Interpretativo - A criança percebe que há variados enfoques e significações em relação ao computador, já conseguindo discutir os aspectos positivos e negativos do uso da máquina, assim como reconhecendo que o homem não deve "adorá-la", mas apropriar-se dela e dos seus benefícios.

e) Recriativo - Dá-se a incorporação plena e a utilização do computador em suas várias funções. A criança já apresenta preferências claras por atividades e softwares, assim como o desejo de interferir de forma criativa, propondo situações de uso e atividades.

Observamos no primeiro grupo (crianças até seis anos), principalmente nos menores e naqueles que tinham menos familiaridade com o computador, a curiosidade e a atividade exploratória em relação ao mesmo. Nos mais velhos do grupo as características "construtivas" já começavam a aparecer, de forma leve.

No segundo grupo (crianças de seis a onze anos), operatório concretas como dizia Piaget, já pudemos observar a utilização mais pragmática e menos lúdica, característica do estágio construtivo, o interesse classificativo e categorizador e - nas crianças mais velhas - tra- ços do estágio interpretativo: percebendo os diversos usos do computador e criticando-os.

Bastante similar ao que dizia Housen (1992) sobre o estágio interpretativo de apreciação da obra de arte: Viewers attempt to create some kind of
personal encounter with a work of art. They
explore the canvas, letting possible interpre-
tations of the work slowly unfold; they point
out subtleties of line, shape, and color.
Feelings and intuitions take precedence
over critical skills, as these viewers allow the
meaning and symbols of the work to emerge.
Each new encounter with a work of art elicits
new comparisons, insights, and experien-
ces. Viewers accept the idea that the artist's
identity and value are subject to re-inter-
pretation, and see a given interpretation
subject to change.

O terceiro grupo (crianças com mais de onze anos) expressavam essas características interpretativas de forma plena, ao mesmo tempo que as do estágio recriativo, descritas anteriormente.

Não passaram desapercebidas - e algumas foram explicitadas nos resultados da pesquisa apresentados anteriormente - as virtudes da oportunidade de acesso e interação de uma criança com o computador como meio de aprendizagem, com efeitos praticamente inavaliáveis. No dizer de Armstrong e Casement:

Quando as crianças aprendem a usar o computador, elas não estão apenas aprendendo uma técnica, e sim mudando suas próprias relações com o mundo ao seu redor. A maneira como as informações são acessadas, a maneira como são apresentadas, os modos pelos quais podem ser manipuladas, todos alteram as percepções que as crianças têm a respeito do saber e do fazer. (2001, p. 22). 


\section{INFORMÁTICA NA EDUCAÇ̃̃O:}

teoria \& prática Porto Alegre, v.9, n.1, jan.jun. 2006. ISSN 1516-084X

\section{Referências Bibliográficas}

ARMSTRONG, Alison; CASEMENT, Charles. A criança e a máquina: como os computadores colocam a educação de nossos filhos em risco. Porto Alegre: Artes Médicas, 2001.

BELLONI, Maria Luiza. O que é mídia - educação. Campinas: Autores Associados, 2001.

FRAWLEY, William. Vygotsky e a Ciência Cognitiva: Linguagem e integração das mentes social e computacional. Porto Alegre: Artes Médicas, 2000.

HOUSEN, Abigail Housen. The eye of the beholder: Measuring aesthetic development. Cambridge, MA: Harvard University, 1983.

. Validating a Measure of Aesthetic Development for Museums and Schools. ILVS Review.

Milwaukee. v. 2, n. 2, p. 213-237, 1992.

et al. Educação estética e artística: abordagens transdisciplinares. Lisboa: Fundação Calouste Gulbenkian, 2000.

LÉVY, Pierre. As tecnologias da inteligência - o futuro do pensamento na era da informática. Rio de Janeiro: Ed. 34, 1993.

O que é o virtual. São Paulo: Ed 34, 1996.

LUKE, Allan. Text and discourse in education: an introduction to critical discourse analysis. Review of Research in Education. Washington, n. 21, p. 3-48, 1996.

MARTIN, Eustaquio; AHIJADO, Manuel. La educación a distancia en tiempos de câmbios: nuevas generaciones, viejos conflictos. Madrid: Ediciones de la Torre, 1999.

PIAGET, Jean. Adaptación vital y Psicología de la Inteligencia. Madrid: Siglo Veintiuno, 1978.

. O raciocínio na criança. Rio de Janeiro: Record, s.d.

SANTOS, Boaventura de Sousa. Um discurso sobre as Ciências. Porto: Afrontamento, 1996.

SHERMAN. G. Instructionist vs. Constructionist web-based collaborative learning environements. Proceedings of National Convention of the Association for Education Communication and Technology. Atlanta, Georgia, 1999, p. 10-12.

VILLARDI, Raquel M.. Ensinando a gostar de ler e formando leitores para a vida inteira. Rio de Janeiro: Dunya, 1997.

VYGOTSKY, Lev S. A Formação social da Mente: o desenvolvimento dos processos psicológicos superiores. São Paulo: Martins Fontes, 1989.

\section{Eloiza da Silva Gomes de Oliveira}

Universidade do Estado do Rio de Janeiro (UERJ). Faculdade de Educação

E-mail:eloizaoliveira@uol.com.br

Raquel Marques Villardi

Universidade do Estado do Rio de Janeiro (UERJ). Faculdade de Educação.

E-mail: rvillardi@yahoo.com.br 